\title{
A bibliometric analysis of toxicology research productivity in Middle Eastern Arab countries during a 10-year period (2003-2012)
}

Sa'ed H Zyoud ${ }^{1,2,3^{*}}$, Samah W Al-Jabii, Waleed M Sweileh ${ }^{2}$ and Rahmat Awang ${ }^{3}$

\begin{abstract}
Background: Bibliometric studies are increasingly being used for research assessment by involving the application of statistical methods to scientific publications to obtain the bibliographics for each country. The main objective of this study was to analyse the research productivity originating from 13 Middle Eastern Arab (MEA) countries with articles published in toxicology journals.
\end{abstract}

Methods: Data from January 1, 2003 till December 31, 2012 were searched for documents with specific words in the toxicology field as a "source title" in any one of the 13 MEA countries. Research productivity was evaluated based on a methodology developed and used in other bibliometric studies. Research productivity was adjusted to the national population and nominal gross domestic product (GDP) per capita.

Results: Documents $(n=1,240)$ were retrieved from 73 international peer-reviewed toxicology journals. The $h$-index of the retrieved documents was 39. Of the 73 journal titles, 52 (69.9\%) have their IF listed in the ISI Journal Citation Reports 2012; 198 documents (16.0\%) were published in journals that had no official IF. After adjusting for economy and population power, Egypt (193.6), Palestine (18.1), Kingdom of Saudi Arabia (KSA) (13.0), and Jordan (11.5) had the highest research productivity. Countries with large economies, such as the Kuwait, United Arab Emirates (UAE), and Oman, tended to rank relatively low after adjustment of GDP. The total number of citations at the time of data analysis (August 4, 2013) was 10,991, with a median (interquartile range) of 4 (1-11). MEA collaborated more with countries in the MEA regions (16.7\%), especially KSA, Egypt, and UAE, followed by Europe (14.4\%), especially with the United Kingdom and Germany.

Conclusions: The present data show a promising rise and a good start for toxicology research activity in toxicology journals in the Arab world. Research output is low in some countries, which can be improved by investing in more international and national collaborative research projects in the field of toxicology.

Keywords: Bibliometric, Impact factor, Middle Eastern Arab, Scopus, Toxicology

\section{Background}

Bibliometric studies are increasingly being used for research assessment [1] by involving the application of statistical methods to scientific publications to obtain the bibliographics for each country. These methods are mainly quantitative but are also used to make pronouncements

\footnotetext{
* Correspondence: saedzyoud@yahoo.com

${ }^{1}$ Poison Control and Drug Information Center (PCDIC), College of Medicine and Health Sciences, An-Najah National University, Nablus 44839, Palestine ${ }^{2}$ Department of Pharmacology and Toxicology, College of Medicine and Health Sciences, An-Najah National University, Nablus 44839, Palestine Full list of author information is available at the end of the article
}

about qualitative pictures of scientific activities [1,2]. Scientific progress is one of the most important indicators for community and economic development of different countries [3]. Well-known databases, such as PubMed, Scopus, Web of Science (i.e., Thomson Reuters Institute for Scientific Information [ISI]), and Google Scholar index international publications in biomedical sciences [4].

Recently, several studies have measured and analysed the outcome of scientific output from Arab countries in different specialities [2,5-10]. In contrast, the evolution of scientific output in the field of toxicology has been poorly explored to date and there are few internationally 
published reports on research activity in toxicology [11-16]. To the best of our knowledge, there is a lack of data concerning the evaluation of research productivity in toxicology originating from the Arab world.

Thus, estimates of Arab productivity of ongoing research in the field of toxicology may be of interest. In this bibliometric analysis, we sought to evaluate the contribution of different Middle Eastern Arab (MEA) countries in the scientific research field as published in toxicology journals, and as represented by the quantity and quality of published papers. Bibliometric analysis is a useful tool to obtain information about the current state of research in particular areas and allows researchers to identify and undertake new lines of research [17]. This type of analysis is a research method used in library and information sciences and utilises quantitative analysis and statistics to obtain the bibliographical works within a given field, topic, institute, or country [18-20]. The most important bibliometric indicators for research capacity and productivity include the number of publications, the amount of peerreviewed scientific journal articles, the number of total citations, and the type of publications [20-22]. Such a study will lead to a better understanding of the current and future status of toxicology in the Middle East. Furthermore, evaluation of toxicological research output in the Arab world is important for monitoring and improving this activity; this could help in putting research activities in the Arab countries into perspective.

\section{Methods}

This study obtained data from Scopus published from January 1, 2003 till December 31, 2012. It is assumed that the last decade would project a better picture of the pattern of publications and the citations received. A comprehensive online search was performed using SciVerse, Scopus, which is one of the world's largest abstract and citation databases of peer-reviewed literature. Scopus contains 41 million records and covers nearly 18,000 titles from 5,000 publishers worldwide, and provides $100 \%$ MEDLINE coverage [23]. The Scopus database was developed by Elsevier and combines the characteristics of both Web of Science and PubMed. These characteristics allow for enhanced service for educational and academic needs, medical literature research, and bibliometric analysis. Scopus offers a basic search or an advanced search options. In the basic search, the results for the chosen keywords can be limited by the date of publication, by addition to Scopus, by subject area, and by document type [24]. The search output from Scopus can be presented as a list of 20 to 200 items per page, and extracted documents can be exported to Microsoft Office Excel ${ }^{\circ}$. The results can be refined by document type, author name, source title, publications per year, and/or subject area, and a new search can be initiated within the results [24].
The key words entered in Scopus to accomplish the objective of this study were "Toxicology", "Toxicological", and "Toxic", "toxicon", "toxin", "toxins", "ecotoxicology", "nanotoxicology", and "neurotoxicology" as Source Title. Then, all 13 Arab countries in the Middle East were entered as country affiliation (i.e., Egypt, Syrian Arab Republic [SAR], Lebanon, Jordan, Iraq, Kingdom of Saudi Arabia [KSA], Kuwait, Bahrain, State of Palestine, United Arab Emirates [UAE], Yemen, Oman, and Qatar). The subject areas selected for this research were: health sciences, life sciences, social sciences, and physical sciences. The resultant search was as follows: your query: (SRCTITLE(toxicology) OR SRCTITLE(toxicological) OR SRCTITLE(toxic) OR SRCTITLE(toxicon) OR SRCTITLE (toxin) OR SRCTITLE(toxins) OR SRCTITLE(ecotoxicology) OR SRCTITLE(nanotoxicology) OR SRCTITLE (neurotoxicology) AND AFFILCOUNTRY(Jordan) OR AFFILCOUNTRY(Egypt) OR AFFILCOUNTRY(United Arab Emirates) OR AFFILCOUNTRY(Saudi Arabia) OR AFFILCOUNTRY(Palestine) OR AFFILCOUNTRY(Bahrain) OR AFFILCOUNTRY(Yemen) OR AFFILCOUNTRY(Syrian) OR AFFILCOUNTRY(Iraq) OR AFFILCOUNTRY(Kuwait) OR AFFILCOUNTRY(Oman) OR AFFILCOUNTRY(Lebanon) OR AFFILCOUNTRY (Qatar)) AND PUBYEAR > 2002 AND PUBYEAR <2013. We excluded documents published as errata.

The collected data were used to generate the following information: (a) total and trends of contributions in toxicology fields between 2003 and 2012; (b) MEA authorship pattern and productivity; (c) collaboration patterns; (d) journals in which MEA researchers publish; (e) the classification of journals as ISI or non-ISI; (f) impact factors (IFs) of all publications; (g) number of citations received by the publications; and (h) areas of interest for published papers.

\section{Ethical approval}

Institutional Review Board (IRB) approval exemptions were obtained by authors from An-Najah National University. The IRB considered waiving the requirement to get approval exemptions for protocols that were clearly below minimal risk, and the current research did not involve any interactions with human participants and used a secondary data set.

\section{Statistical analysis}

Data from Scopus were exported to Excel and then to the Statistical Package for Social Sciences (SPSS; SPSS Inc., Chicago, IL, USA) program version 15 for analysis. Continuous data are presented as mean \pm standard deviation (SD), and categorical data are expressed as numbers with percentages. Variables that are not normally distributed are expressed as median (Q1-Q3: interquartile range). The $h$-index for the data collected from SCOPUS is 
presented. The $h$-index represents the number of citations received for each of the articles in descending order and the $h$-graph measures the impact of a set of documents and displays the number of citations per article. The journal's IF was evaluated using the Journal Citation Report (JCR; Web of Knowledge) 2012 science edition by Thomson Reuters (New York, NY, USA). Publication activity was adjusted for the 13 MEA countries categorized by population size and gross domestic product (GDP) retrieved from the online databases of the World Bank [25]. An adjustment index (AI) was calculated using the following formula: $\mathrm{AI}=$ [total number of publications for the country/GDP per capita of the country]"1,000. Where GDP per capita $=$ GDP $/$ population of the country [5].

\section{Results}

The total number of documents which were published in toxicology journals obtained by entering the word "toxicology" and related terms in the Scopus search engine as a source title without specifying the name of any country was 74,468 documents. This number represents the total global research productivity in toxicological journals during the past decade. Using the methodology stated above, only 1,240 (1.66\% from the total global research productivity in toxicology journals) documents from 13 MEA countries were retrieved, comprising 1,158 (93.4\%) original journal articles; $33(2.7 \%)$ review articles; 27 (2.2\%) meeting/conference abstracts; 12 (1.0\%) letters; and $10(0.8 \%)$ other types of publications, with an average of 124 documents per year. According to Scopus, the 13 MEA countries produced 60,477 biomedical publications during 2003-2012, which is around 49 times higher than those produced in toxicology journals.

Table 1 shows the annual number of documents published in the past decade (2003-2012). The results indicate that publications in toxicology journals during the past decade were low in the first few years but showed an obvious doubling after 2009. The quantity of publications has increased by around three-fold from 2003 to 2012.

The retrieved documents were published in 73 international peer-reviewed toxicology journals out of 102 peerreviewed toxicology journals registered in Scopus (Table 2); 143 articles (11.5\%) were published in Food and Chemical Toxicology whereas $72(5.8 \%)$ were published in the Journal of Environmental Science and Health, Part A: Toxic Hazardous Substances and Environmental Engineering, and 71 (5.7\%) were published in the Bulletin of Environmental Contamination and Toxicology journal. This was followed by 63 (5.1\%) published in Toxicological and Environmental Chemistry, 46 (3.7\%) published in Toxicon, 45 (3.6\%) published in Toxicology, and 41 (3.3\%) published in Ecotoxicology and Environmental Safety. Of the 73 journal titles, 52 (69.9\%) have their IF listed in the JCR 2012; 198 documents (16.0\%) were published in journals that had no official IF
Table 1 Annual number of toxicology-based publications in 13 Middle Eastern Arab countries

\begin{tabular}{ll}
\hline Year & $\begin{array}{l}\text { Total } \\
\mathbf{n}=\mathbf{1 2 4 0}(\%)\end{array}$ \\
\hline 2003 & $83(6.7)$ \\
2004 & $85(6.9)$ \\
2005 & $56(4.5)$ \\
2006 & $81(6.5)$ \\
2007 & $91(7.3)$ \\
2008 & $101(8.1)$ \\
2009 & $139(11.2)$ \\
2010 & $193(15.6)$ \\
2011 & $197(15.9)$ \\
2012 & $214(17.3)$ \\
\hline
\end{tabular}

(Table 2). Only 21documents were published in the three journals with an IF $>5$.

When the data were analysed by country, the highest number of publications in toxicology journals was from Egypt (49.8\%), followed by KSA (26.3), UAE (11.5\%), and Jordan (4.8\%) (Table 3). After adjusting for economy and population power, Egypt (193.6), Palestine (18.1), KSA (13.0), and Jordan (11.5) had the highest research productivity. Countries with large economies, such as the Kuwait, UAE, and Oman tended to rank relatively low after the adjustment of GDP (Table 3). The total number of citations, at the time of data analysis (August 4, 2013), was 10,991, with a mean \pm SD of $8.8 \pm 15.0$ and median (interquartile range) of $4(1-11)$. The highest median (interquartile range) number of citations was $9(1.8-21)$ for Lebanon, followed by 7.5 (3-16) for UAE, 7 (3-14) for Oman. The lowest median (interquartile range) number of citations was $1(0.0-3.8)$ for Iraq and $1(0.0-5.5)$ for Qatar. Furthermore, the highest median (interquartile range) IF was 2.8 (2.1-3.0) for Lebanon, followed by 2.7 (1.3-3.1) for Oman, and the lowest median (interquartile range) IF was 1 (0.02.0) for Bahrain.

Of the 1,240 documents considered for the $h$-index, 39 had been cited at least 39 times at the time of data analysis (August 4, 2013). The highest $h$-index was 33 for Egypt, followed by 21 for KSA, 21 for the UAE, and the lowest $h$ index was 2 for Bahrain. The highest percentage of documents indexed in ISI from the total number of documents for each country was $99.4 \%$ for Palestine, followed by $93.5 \%$ for Lebanon, $93.3 \%$ for Kuwait, and the lowest was $53.8 \%$ for Qatar. Furthermore, regarding the countries that have the highest collaborations with international authors, all the documents from Yemen were published with international collaboration followed by documents from SAR (9/10, 90.0\%).

The study identified 471 (38\%) documents with 56 countries in MEA-foreign country collaborations. MEA 
Table 2 List of journals in which the 1,240 documents were published with their corresponding impact factors

\section{Journal}

Food and Chemical Toxicology

Journal of Environmental Science and Health, Part A: Toxic Hazardous Substances and Environmental Engineering

Bulletin of Environmental Contamination and Toxicology

Toxicological and Environmental Chemistry

Toxicon

Toxicology

Ecotoxicology and Environmental Safety

Journal of Applied Toxicology

Mutation Research Genetic Toxicology and Environmental Mutagenesis

Toxicology and Industrial Health

Environmental Toxicology and Pharmacology

Basic and Clinical Pharmacology and Toxicology

Human and Experimental Toxicology

Journal of Biochemical and Molecular Toxicology

Comparative Biochemistry and Physiology C: Toxicology and Pharmacology

American Journal of Pharmacology and Toxicology

Toxicology and Applied Pharmacology

Toxicology Letters

Research Journal of Environmental Toxicology

Archives of Toxicology

Neurotoxicology

Toxicology In Vitro

Archives of Environmental Contamination and Toxicology

Drug and Chemical Toxicology

Journal of Toxicological Sciences

Journal of Pharmacology and Toxicology

Chemical Research in Toxicology

Toxicology Mechanisms and Methods

Inhalation Toxicology

Journal of Venomous Animals and Toxins Including Tropical Diseases

Aquatic Toxicology

Reproductive Toxicology

Practice Periodical of Hazardous Toxic and Radioactive Waste Management

Toxicological Sciences

Clinical Toxicology

Indian Journal of Forensic Medicine and Toxicology

Environmental Toxicology and Chemistry

International Journal of Toxicology

Environmental Toxicology

Journal of Toxicology and Environmental Health Part A: Current Issues

Journal of Toxicology

Journal of Pharmacological and Toxicological Methods

Journal of Analytical Toxicology

Birth Defects Research Part B Developmental and Reproductive Toxicology

\section{Frequency}

IF $(2012)^{*}$

143

3.01

72

1.252

71

1.105

63

NA

46

2.924

45

4.017

41

2.597

37

2.22

1.555

2.005

2.124

1.453

1.596

2.707

NA

3.975

3.145

NA

5.215

2.652

2.65

2.012

1.293

1.380

NA

3.667

1.367

1.894

0.545

3.73

3.141

NA

4.328

2.592

NA

2.618

1.346

2.708

1.733

NA

2.150

2.107

1.971 
Table 2 List of journals in which the 1,240 documents were published with their corresponding impact factors (Continued)

\begin{tabular}{|c|c|c|}
\hline Journal of Occupational Medicine and Toxicology & 6 & 1.403 \\
\hline Cutaneous and Ocular Toxicology & 6 & 1.044 \\
\hline Forensic Toxicology & 5 & 3.194 \\
\hline Journal of Environmental Pathology Toxicology and Oncology & 5 & 0.919 \\
\hline Toxicological Research & 5 & NA \\
\hline Toxicology International & 5 & NA \\
\hline Ecotoxicology & 4 & 2.773 \\
\hline Cell Biology and Toxicology & 4 & 2.338 \\
\hline Regulatory Toxicology and Pharmacology & 4 & 2.132 \\
\hline Toxins & 4 & 2.129 \\
\hline Internet Journal of Toxicology & 4 & NA \\
\hline Journal of Medical Toxicology & 4 & NA \\
\hline Veterinary and Human Toxicology & 4 & NA \\
\hline Journal of Environmental Science and Health Part C: Environmental Carcinogenesis and Ecotoxicology Reviews & 3 & 3.565 \\
\hline Neurotoxicology and Teratology & 3 & 3.181 \\
\hline Interdisciplinary Toxicology & 3 & 1.346 \\
\hline Journal of Forensic Medicine and Toxicology & 3 & NA \\
\hline Expert Opinion on Drug Metabolism and Toxicology & 2 & 2.944 \\
\hline Cardiovascular Toxicology & 2 & 2.351 \\
\hline International Journal of Medical Toxicology and Legal Medicine & 2 & NA \\
\hline Journal of Hazardous Toxic and Radioactive Waste & 2 & NA \\
\hline Toxicology and Environmental Health Sciences & 2 & NA \\
\hline Particle and Fibre Toxicology & 1 & 9.178 \\
\hline Nanotoxicology & 1 & 7.844 \\
\hline Reviews of Environmental Contamination and Toxicology & 1 & 4.125 \\
\hline International Journal of Toxicological and Pharmacological Research & 1 & NA \\
\hline Research Communications in Pharmacology and Toxicology & 1 & NA \\
\hline Research Journal of Toxins & 1 & NA \\
\hline Therapeutics Pharmacology and Clinical Toxicology & 1 & NA \\
\hline
\end{tabular}

NA, Not available; IF, Impact factor.

*The IF was reported according to Institute for Scientific Information journal citation reports 2012.

actively collaborated with authors from the United States of America $(\mathrm{n}=129$, the highest number recorded), followed by the United Kingdom ( $\mathrm{n}=48)$, India $(\mathrm{n}=48)$, Germany $(\mathrm{n}=41)$, Canada $(\mathrm{n}=36)$, France $(\mathrm{n}=33)$, Japan $(\mathrm{n}=29)$, China $(\mathrm{n}=26)$, and Malaysia $(\mathrm{n}=22)$ (Table 4). By region, MEA collaborated most with countries in Europe (14.4\%), especially the United Kingdom and Germany (Table 4). Table 5 presents the areas of interest of the scientific articles. Pharmacology and pharmaceutics was the most researched topic, represented by 1,006 $(81.1 \%)$ articles. The second most researched topic was environmental science 699 (56.4\%) followed by agricultural and biological sciences 167 (13.5\%) articles. On the other hand, topics such as chemistry or epidemiology and social sciences ranked low in their contribution to research output. Furthermore, Table 6 shows the first prolific toxicology authors from the 13 MEA countries with their affiliations and publication patterns. Table 7 presents a list of the 20 most cited articles originating from the 13 MEA countries.

\section{Discussion}

This study was limited to 1,240 documents extracted from Scopus, bearing MEA countries affiliation addresses and, therefore, cannot be generalised to the toxicological literature covered by other databases such as Google Scholar. However, the study does give a clear picture about the characteristics of the documents from MEA countries published in foreign indices, especially those indexed by Scopus. Although the number of citations for each 
Table 3 Bibliometric analysis of the 1,240 documents by country

\begin{tabular}{|c|c|c|c|c|c|c|c|c|c|}
\hline Country & $\begin{array}{l}\text { Number of documents } \\
n=1,240^{\mathrm{a}}(\%)^{\mathrm{a}}\end{array}$ & $\begin{array}{l}\text { Total } \\
\text { citations }\end{array}$ & $\begin{array}{l}\text { Median } \\
\text { (Q1-Q3) citation }\end{array}$ & $\begin{array}{l}\text { Total } \\
\text { IF }\end{array}$ & $\begin{array}{l}\text { Median } \\
\text { (Q1-Q3) IF }\end{array}$ & $\mathrm{H}$ index & $\begin{array}{l}\text { Number }(\%)^{\mathrm{b}} \text { of } \\
\text { documents indexed in ISI }\end{array}$ & $\begin{array}{l}\text { Number }(\%)^{c} \text { of documents } \\
\text { with international authors }\end{array}$ & $\begin{array}{l}\text { Adjustment } \\
\text { index }^{d}\end{array}$ \\
\hline Egypt & $617(49.8)$ & 5702 & $4(1-11)$ & 1277 & $2.2(1.1-3.0)$ & 33 & $553(89.6)$ & $247(40.0)$ & 193.6 \\
\hline KSA & $326(26.3)$ & 2098 & $3(1-7.5)$ & 631.6 & $2.0(1.1-3.0)$ & 21 & $291(89.3)$ & $179(54.9)$ & 13.0 \\
\hline UAE & $142(11.5)$ & 1691 & $7.5(3-16)$ & 324.9 & $2.6(1.4-3.0)$ & 21 & $128(90.1)$ & $94(66.2)$ & 3.8 \\
\hline Jordan & $57(4.6)$ & 217 & $2(0-6)$ & 76.7 & $1.3(0.0-2.1)$ & 8 & $46(80.7)$ & 33 (57.9) & 11.5 \\
\hline Kuwait & $60(4.8)$ & 471 & $4(1.3-11)$ & 100.5 & $1.4(1.3-2.2)$ & 13 & $56(93.3)$ & $26(43.3)$ & 1.2 \\
\hline Lebanon & $46(3.7)$ & 893 & $9(1.8-21)$ & 121.7 & $2.8(2.1-3.0)$ & 14 & $43(93.5)$ & $25(54.3)$ & 4.7 \\
\hline Oman & $34(2.9)$ & 538 & $7(3-14)$ & 82.8 & $2.7(1.3-3.1)$ & 11 & $30(88.2)$ & $25(73.5)$ & 1.6 \\
\hline Iraq & $20(1.6)$ & 54 & $1(0.0-3.8)$ & 24.6 & $1.2(0.0-1.8)$ & 4 & $13(65.0)$ & $10(50.0)$ & 3.1 \\
\hline Palestine & $18(1.5)$ & 128 & $3.5(1.8-10.3)$ & 33.1 & $2.1(1.4-2.2)$ & 6 & 17 (94.4) & $11(61.1)$ & 18.1 \\
\hline Qatar & $13(1.0)$ & 49 & $1(0.0-5.5)$ & 17.4 & $1.1(0.0-2.8)$ & 4 & $7(53.8)$ & $9(69.2)$ & 0.2 \\
\hline SAR & $10(0.8)$ & 35 & $4(1.5-5.3)$ & 22.2 & $2.6(1.7-3.0)$ & 4 & $9(90.0)$ & $9(90.0)$ & 3.0 \\
\hline Yemen & $9(0.7)$ & 66 & $5(1.5-10)$ & 15.2 & $2.0(0.0-2.8)$ & 5 & $7(77.8)$ & $9(100)$ & 6.0 \\
\hline Bahrain & $4(0.3)$ & 7 & $2(0.0-2.7)$ & 4.25 & $1.0(0.0-2.0)$ & 2 & $3(75.0)$ & $1(25)$ & 0.2 \\
\hline
\end{tabular}

IF, Impact factor; ISI,Institute for Scientific Information; UAE, United Arab Emirates; KSA, Kingdom of Saudi Arabia; SAR, Syrian Arab Republic; Q1-Q3, Lower quartile - upper quartile.

${ }^{a}$ Total exceeds $100 \%$ because data are overlapping due to multiple collaborations.

Percentage of documents indexed in ISI from the total number of documents for each country.

'Percentage of documents with international authors from the total number of documents for each country

${ }^{\mathrm{d}} \mathrm{An}$ Al was calculated using the following formula: Al $=$ [total number of publications for the country/GDP per capita of the country]*1,000. Where: GDP per capita $=$ GDP/population of the country. 
Table 4 Collaborations between the 13 Middle Eastern Arab countries and foreign countries in toxicological publications

\begin{tabular}{|c|c|c|c|}
\hline Collaborating countries $^{a}$ & No. of documents & Collaborating countries a & No. of documents \\
\hline MEA-MEA & $116(9.4 \%)$ & MEA-Asia-Pacific & $137(11.0 \%)^{*}$ \\
\hline Egypt & 84 & India & 48 \\
\hline Saudi Arabia & 79 & Japan & 29 \\
\hline United Arab Emirates & 26 & China & 26 \\
\hline Kuwait & 5 & South Korea & 15 \\
\hline Jordan & 13 & Pakistan & 10 \\
\hline Lebanon & 2 & Taiwan & 4 \\
\hline Oman & 17 & Australia & 4 \\
\hline Qatar & 9 & New Zealand & 3 \\
\hline Syrian Arab Republic & 3 & Bangladesh & 2 \\
\hline Yemen & 2 & Hong Kong & 2 \\
\hline Bahrain & 1 & New Caledonia & 1 \\
\hline MEA-other Middle East, Africa & $55(4.4 \%)^{*}$ & French Polynesia & 1 \\
\hline Turkey & 14 & MEA-Europe & $178(14.4 \%)^{*}$ \\
\hline Iran & 9 & United Kingdom & 48 \\
\hline Tunisia & 8 & Germany & 41 \\
\hline Libyan Arab Jamahiriya & 5 & France & 33 \\
\hline Sudan & 5 & Czech Republic & 13 \\
\hline Ethiopia & 4 & Belgium & 10 \\
\hline South Africa & 3 & Austria & 9 \\
\hline Zimbabwe & 3 & Netherlands & 8 \\
\hline Israel & 2 & Denmark & 8 \\
\hline Algeria & 2 & Italy & 8 \\
\hline Ghana & 2 & Spain & 6 \\
\hline Guinea & 1 & Ireland & 5 \\
\hline Nigeria & 1 & Sweden & 5 \\
\hline Zambia & 1 & Finland & 4 \\
\hline MEA-Americas & $150(12.1 \%)^{*}$ & Switzerland & 4 \\
\hline United States & 129 & Hungary & 3 \\
\hline Canada & 36 & Bulgaria & 1 \\
\hline Puerto Rico & 2 & Serbia & 1 \\
\hline Brazil & 1 & Slovakia & 1 \\
\hline MEA-Southeast Asia & $25(2.0 \%)^{*}$ & Bosnia and Herzegovina & 1 \\
\hline Malaysia & 22 & Romania & 1 \\
\hline Thailand & 2 & Albania & 1 \\
\hline \multirow[t]{2}{*}{ Singapore } & 1 & Poland & 1 \\
\hline & & Croatia & 1 \\
\hline
\end{tabular}

MEA, Middle Eastern Arab countries.

${ }^{a}$ The study identified 471 (38\%) documents with 56 countries in MEA-foreign country collaborations.

*Total exceeds $38 \%$ as data are overlapping due to multi-country collaboration.

publication might differ from one search engine to another, the Scopus search engine remains one of the best available tools for analysing and tracking citations, and comparing citations among different research groups and different institutions [26]. A study that compared
PubMed, Scopus, Web of Knowledge, and Google Scholar has found that PubMed remains an important resource for clinicians and researchers, while Scopus covers a wider journal range and offers the capability for citation analysis [4,26-28]. 


\begin{tabular}{ll}
$\begin{array}{l}\text { Table } \mathbf{5} \text { Areas of interest for published papers by the } \mathbf{1 3} \\
\text { Middle Eastern Arab countries }\end{array}$ \\
\hline Areas of interest & $\mathbf{n}(\%)^{*}$ \\
\hline Pharmacology and Pharmaceutics & $1006(81.1)$ \\
Environmental Science & $699(56.4)$ \\
Agricultural and Biological Sciences & $167(13.5)$ \\
Medicine & $165(13.3)$ \\
Biochemistry, Genetics and Molecular Biology & $115(9.3)$ \\
Chemical Engineering & $30(2.4)$ \\
Neuroscience & $22(1.8)$ \\
Chemistry & $17(1.4)$ \\
Social Sciences and Epidemiology & $15(1.2)$ \\
Planetary Sciences & $13(1.1)$ \\
Immunology & $12(1.1)$ \\
Veterinary & $4(0.3)$ \\
\hline
\end{tabular}

*Total exceeds $100 \%$ as data are overlapping due to multidiscipline interaction.

In the present study, bibliometric indicators were used to describe scientific activity in the field of toxicology in 13 MEA countries during the last decade. Based on the authors' knowledge, this is the first article to analyse the quantity and quality of toxicology-based research from the Arab world. Research indicators showed that research activity in this field was neglected in most MEA countries. The total publications found in Scopus between 2003 and 2012 showed a yearly increase. Most countries experienced increases in the absolute number of documents produced in the field of toxicology over time. Furthermore, the current study showed low research output in some countries. In our study, we compared the toxicological research performance in the MEA countries with that in non-MEA countries. The study shows that MEA countries are lagging behind in the number of toxicological research publications. Furthermore, they are also lagging behind when the number of toxicological publications in the MEA countries is compared with other biomedical research publications in the same region. Toxicology productivity has followed the general explosion in scientific productivity observed in the last decade and especially in recent years $[5,11,13]$ as well as following the biomedical research performance in the Arab world in the last decades $[5,29,30]$.

Bibliometric descriptors for documents published by toxicologists and in toxicology journals are presented in Tables 3 and 5. As can be seen, each country's behaviour was different. Our study showed that there were some countries, such as Egypt and KSA, where their total toxicology productivity during this 10-year period was clearly higher than in the remaining countries. Previous studies reported that Egypt and KSA had the most biomedical publications among the Arab countries [29,31].
Our results are similar, as these two countries had the highest number of toxicological research publications in the Arab world. In our study, the ranking of countries after adjusting for economy and population parameters differed conspicuously from those based on absolute production. After adjusting for economy and population power, Egypt, Palestine, KSA, and Jordan had the highest research productivity. We did not find any study similar to ours, thus we are unable to discuss this point in light of other results. However, some studies using the same tool for analysis have reported similar findings $[5,10,29,30,32,33]$. Countries with rapidly growing economies, which results in more funding and investments for research, contribute to the tendency of increasing number of toxicology publications such as KSA. Based on our findings, besides GDP, population size is one of the main factors related to research productivity, as was observed for Egypt; this activity depended on population size, socio-economic status, or overall scientific activity of the country [11]. The annual number of documents published indicates that research productivity in toxicology journals during the past decade was low. Several studies have discussed the reasons leading to the scarcity of medical research in most Arab regions [5,10,29,30]. These studies suggested that the regional conflict has been considered a main cause for the paucity of medical publications in some Arab countries. Furthermore, a lack of funding, freedom, and democracy may contribute to low scientific research output in the Arab world $[10,29,30]$. All these reasons have to be taken into consideration if the governments in the Arab regions wish to develop the status of their scientific research output.

In our study, the average citation rate for publications from MEA countries was 8.8 citations per article. This finding was consistent with general average citations of toxicological journals [15,34]. Furthermore, this is slightly less than the average citation rate for most journals in other scientific disciplines [15,34]. Overall, toxicology journals as a group have low citation numbers compared to other scientific disciplines. This is likely attributed to several facts. First, the number of researchers of toxicology is small, leading to relatively fewer publications being published in peer-reviewed toxicology journals compared with other disciplines. Second, the apparent narrow focus of toxicology journals may encourage researchers who have some connection to the field of toxicology to publish their results in journals that may have a larger audience than that of toxicology journals $[15,35]$. This exact scenario was demonstrated in the emergency medicine literature by Callaham et al. [36]; they found that publications by emergency medicine researchers were cited more than two times as often when published in non-emergency medicine journals. 
Table 6 The first prolific toxicology authors from the 13 Middle Eastern Arab countries with their affiliations and publication patterns

\begin{tabular}{|c|c|c|c|c|c|}
\hline Country & $\begin{array}{l}\text { Total publications } \\
\text { for the country }\end{array}$ & Author & $\begin{array}{l}\text { No. }(\%)^{\mathrm{a}} \text { of toxicology } \\
\text { publications }\end{array}$ & $\begin{array}{l}\text { Total publications } \\
\text { for author }\end{array}$ & Affiliation \\
\hline Egypt & 617 & Yousef, M.I. & $29(4.7)$ & 41 & Alexandria University, Department of Environmental Studies, Alexandria \\
\hline KSA & 326 & Gondal, M.A. & $25(7.7)$ & 124 & King Fahd University of Petroleum and Minerals, Department of Physics, Dharan, Saudi Arabia \\
\hline UAE & 142 & Petroianu, G.A. & $26(18.3)$ & 112 & $\begin{array}{l}\text { Faculty of Medicine and Health Sciences, United Arab Emirates University, } \\
\text { Department of Pharmacology and Therapeutics, United Arab Emirates }\end{array}$ \\
\hline Jordan & 57 & Maslat, A.O. & $8(14.0)$ & 8 & Yarmouk University, Department of Biological Sciences, Irbid, Jordan \\
\hline Kuwait & 60 & Narayana, K. & $7(11.7)$ & 47 & Health Sciences Center Kuwait Faculty of Medicine, Department of Anatomy, Safat, Kuwait \\
\hline Lebanon & 46 & Shihadeh, A. & $12(26.1)$ & 32 & American University of Beirut, Department of Mechanical Engineering, Beirut, Lebanon \\
\hline Oman & 34 & Ali, B.H. & $17(50.0)$ & 58 & Sultan Qaboos University, Department of Pharmacology, Muscat, Oman \\
\hline Iraq & 20 & Mohammad, F.K. & $5(25.0)$ & 26 & University of Mosul, Department of Physiology, Biochemistry and Pharmacology, Mosul, Iraq \\
\hline Palestine & 18 & Zyoud, S.H. & $6(33.3)$ & 49 & $\begin{array}{l}\text { Poison Control and Drug Information Center (PCDIC), College of Medicine and } \\
\text { Health Sciences, An-Najah National University, Nablus, Palestine }\end{array}$ \\
\hline Qatar & 13 & Busselberg, D. & $3(23.1)$ & 3 & Weill Cornell Medical College in Qatar, Doha, Qatar \\
\hline SAR & 10 & Ahmed, S. & $4(40.0)$ & 21 & International Center for Agricultural Research in the Dry Areas Syria, Aleppo, Syrian Arab Republic \\
\hline Yemen & 9 & Al-Zubairi, A.S. & $2(22.2)$ & 29 & Sana'a University, Faculty of Medicine, Sana'a, Yemen \\
\hline Bahrain & 4 & Sequeira, R.P. & $1(25.0)$ & 42 & Arabian Gulf University, Department of Pharmacology and Therapeutics, Manama, Bahrain \\
\hline
\end{tabular}

UAE, United Arab Emirates; KSA, Kingdom of Saudi Arabia; SAR, Syrian Arab Republic.

a Percentage of toxicology publications for the first prolific toxicology author from the total number of documents for each country.

${ }^{\mathrm{b}}$ Total of all publications for each author during the period of study. 
Table 7 The top 20 cited toxicology articles from the 13 Middle Eastern Arab countries in Scopus

\begin{tabular}{|c|c|c|c|c|}
\hline $\mathrm{SCR}^{\mathrm{a}}$ & Authors and year of publication & Title & Journal name & Times cited $^{\mathbf{b}}$ \\
\hline $1^{\text {st }}$ & Ali et al., 2008 & $\begin{array}{l}\text { Some phytochemical, pharmacological and toxicological properties } \\
\text { of ginger (Zingiber officinale Roscoe): A review of recent research }\end{array}$ & Food and Chemical Toxicology & 191 \\
\hline $2^{\text {nd }}$ & El-Demerdash et al., 2004 & $\begin{array}{l}\text { Cadmium-induced changes in lipid peroxidation, blood hematology, } \\
\text { biochemical parameters and semen quality of male rats: protective } \\
\text { role of vitamin } E \text { and } \beta \text {-carotene }\end{array}$ & Food and Chemical Toxicology & 175 \\
\hline $3^{\text {rd }}$ & Shihadeh, 2003 & Investigation of mainstream smoke aerosol of the argileh water pipe & Food and Chemical Toxicology & 162 \\
\hline $4^{\text {th }}$ & El-Demerdash, 2005 & $\begin{array}{l}\text { Biochemical study on the hypoglycemic effects of onion and garlic } \\
\text { in alloxan-induced diabetic rats }\end{array}$ & Food and Chemical Toxicology & 153 \\
\hline $5^{\text {th }}$ & Shihadeh and Saleh, 2005 & $\begin{array}{l}\text { Polycyclic aromatic hydrocarbons, carbon monoxide, 'tar', and nicotine } \\
\text { in the mainstream smoke aerosol of the narghile water pipe }\end{array}$ & Food and Chemical Toxicology & 147 \\
\hline $6^{\text {th }}$ & Jurjus et al., 2004 & Animal models of inflammatory bowel disease & $\begin{array}{l}\text { Journal of Pharmacological and } \\
\text { Toxicological Methods }\end{array}$ & 124 \\
\hline $7^{\text {th }}$ & Badary et al., 2003 & Thymoquinone is a potent superoxide anion scavenger & Drug and Chemical Toxicology & 101 \\
\hline $7^{\text {th }}$ & Mohamed et al., 2003 & $\begin{array}{l}\text { Estimation of microcystins in the freshwater fish Oreochromis niloticus in } \\
\text { an Egyptian fish farm containing a Microcystis bloom }\end{array}$ & Environmental Toxicology & 101 \\
\hline $9^{\text {th }}$ & Ali and Al Moundhri, 2006 & $\begin{array}{l}\text { Agents ameliorating or augmenting the nephrotoxicity of cisplatin and } \\
\text { other platinum compounds: a review of some recent research }\end{array}$ & Food and Chemical Toxicology & 98 \\
\hline $10^{\text {th }}$ & Radwan and Salama, 2006 & Market basket survey for some heavy metals in Egyptian fruits and vegetables & Food and Chemical Toxicology & 82 \\
\hline $11^{\text {th }}$ & Ali, 2003 & $\begin{array}{l}\text { Agents ameliorating or augmenting experimental gentamicin nephrotoxicity: } \\
\text { some recent research }\end{array}$ & Food and Chemical Toxicology & 79 \\
\hline $12^{\text {th }}$ & Yousef, 2004 & $\begin{array}{l}\text { Aluminium-induced changes in hemato-biochemical parameters, lipid peroxidation } \\
\text { and enzyme activities of male rabbits: protective role of ascorbic acid }\end{array}$ & Toxicology & 77 \\
\hline $13^{\text {th }}$ & Yousef et al., 2006 & $\begin{array}{l}\text { Deltamethrin-induced oxidative damage and biochemical alterations in } \\
\text { rat and its attenuation by Vitamin } \mathrm{E}\end{array}$ & Toxicology & 72 \\
\hline $14^{\text {th }}$ & Shalan et al., 2005 & Amelioration of lead toxicity on rat liver with Vitamin $C$ and silymarin supplements & Toxicology & 71 \\
\hline $15^{\text {th }}$ & Abdel-Wahhab and Aly, 2005 & $\begin{array}{l}\text { Antioxidant property of Nigella sativa (black cumin) and Syzygium aromaticum } \\
\text { (clove) in rats during aflatoxicosis }\end{array}$ & Journal of Applied Toxicology & 69 \\
\hline $16^{\text {th }}$ & El-Sharaky et al., 2007 & Protective role of selenium against renal toxicity induced by cadmium in rats & Toxicology & 67 \\
\hline $17^{\text {th }}$ & Mansour, 2004 & Pesticide exposure - Egyptian scene & Toxicology & 61 \\
\hline $17^{\text {th }}$ & Yousef et al., 2003 & $\begin{array}{l}\text { Changes in some hematological and biochemical indices of rabbits induced } \\
\text { by isoflavones and cypermethrin }\end{array}$ & Toxicology & 61 \\
\hline $19^{\text {th }}$ & Raza and John, 2006 & $\begin{array}{l}\text { 4-Hydroxynonenal induces mitochondrial oxidative stress, apoptosis and expression } \\
\text { of glutathione S-transferase A4-4 and cytochrome P450 2E1 in PC12 cells }\end{array}$ & Toxicology and Applied Pharmacology & 60 \\
\hline $20^{\text {th }}$ & Sepetdjian et al., 2008 & Measurement of 16 polycyclic aromatic hydrocarbons in narghile waterpipe tobacco smoke & Food and Chemical Toxicology & 57 \\
\hline
\end{tabular}

SCR, Standard Competition Ranking.

${ }^{\mathrm{a} E q u a l}$ articles have the same ranking number, and then a gap is left in the ranking numbers.

${ }^{\mathrm{b}}$ Time cited at the time of data analysis (December 13, 2013). 
The results of this study showed that the most cited articles published from MEA countries were mainly those in the field of public health. It was very striking that three articles from the top 20 cited articles published from MEA countries were articles related to tobacco smoking. Smoking is considered a major risk factor for several major diseases including heart disease, cancer, and chronic obstructive pulmonary disease, and is also the most preventable cause of morbidity and mortality contributing to around half a million deaths every month, a condition that is definitely to worsen in the future [37]. Tobacco smoking is on rise and as a multi-disciplinary field of study; it has resulted in growing research that takes into account almost all those regions that have experienced the greatest increases in bioscience and healthcare science production.

In the current study, topics such as epidemiology and social sciences ranked low in their contribution to research output in the field of toxicology. One of the scientific challenges of toxicology in the Asian region is the limited availability of epidemiological information. This field of study is neglected in most countries. Unfortunately, most of the available epidemiological data in this region have been published in different formats, and some documents were extracted from files of poisoned patients while others from poison centres, in which the outcome and frequency of poisonings were different. Thus, a clear picture of poisoning epidemiology is necessary in this region [38]. Another possible explanation for this is the lack of peer reviewed local and regional journals that are indexed in Scopus. In 2012, there were 102 journals indexed under "toxicology", but none of them belonged to MEA countries. Thus, MEA countries are recommended to establish peer-reviewed journals to promote science in middle- and low-income countries, which could be submitted for indexing in Scopus. Publication in Asia-specific or regional journals would hopefully serve as another milestone for toxicologists in the region and will promote research about epidemiological interests that have low priorities in higher-income countries' journals [39].

While case reports are often the most read content of journals, and they significantly advance our understanding of a particular clinical toxicology syndrome, treatment, mechanism, or are supportive of a new hypothesis [34] or serve as early warning signals for the adverse effects of new drugs and unique clinical presentations from common drugs [40], they were ranked low in their contribution to research output in the field of toxicology from MEA countries. One possible explanation for this is the low number of publications from MEA countries which were published in clinical or human toxicology journals. The results of our study showed that Food and Chemical Toxicology, Journal of Environmental Science and Health, Part A: Toxic Hazardous Substances and Environmental Engineering, Bulletin of Environmental Contamination and Toxicology journal, Toxicological and Environmental Chemistry, Toxicon, Toxicology, and Ecotoxicology and Environmental Safety have the largest share from MEA countries' publications. These journals were more interested in areas of environmental science, agricultural and biological sciences, biochemistry, genetics and molecular biology, and chemical engineering rather than clinical cases.

It is noteworthy that some MEA authors have succeeded in publishing in high-quality journals like Particle and Fibre Toxicology, Archives of Toxicology, Toxicological Sciences, Nanotoxicology, and Toxicology. International collaborations might help MEA researchers to publish in journals with a high IF. Comparing toxicology to areas such as molecular biology and genetics, where new discoveries are made almost every day, toxicology is a more slowly advancing science. This can result in wide disparities between the citations of journals in different fields in comparison to a journal with a narrow field [34]. This may be one reason why journals like The Lancet, JAMA, Nature, Science, and the New England Journal of Medicine, whose content encompasses the entire scope of medicine and science, are always among the journals with the highest citations, which in turn leads to high IFs. Since toxicology is a very narrow field with a very small and specialized readership, it should not be astonishing that toxicology journals have small numbers of citations, which leads to average IFs $[15,41]$. Therefore, it would have been more interesting to know how the growth of toxicology in these countries was in quality rather than in quantity, as shown by the low median citations and IFs. The preparation of quality research documents requires significant effort and time. Publishing in high-impact journals allows established researchers to be able to obtain further funding to support collaborative research and for young researchers to be more competitive in career advancement [42].

Moreover, MEA authors mainly collaborated with authors from the United States of America, India, United Kingdom, Germany, Canada, China, France, Japan, and Malaysia. This may be because most MEA academics graduated from or were trained in these countries. Investigators who are open to collaborations and those who seem to adequately manage their collaborations produce a superior product that results in a higher impact and higher citation rates [43]. The factors in favour of increasing collaborations internationally cannot be ignored; these are the results of easier access to public financing, opportunities to attain higher productivity, and aspirations for greater prestige and visibility resulting from collaboration with renowned research groups $[44,45]$. In addition to these advantages of collaboration, follow-up research expertise of other countries, developed or developing, is 
another key factor for facilitating applicable and translatable research in countries that historically lack it.

This study shows the first prolific toxicology authors from the 13 MEA countries with their affiliations and publication patterns, indicating their active roles as writers. In most universities worldwide, promotional criteria require academics to show their active involvement in research as reflected by the ranking as first prolific toxicology authors. Often the Deanship of Scientific Research will be asked by university administrators to provide such evidence and the analysis of the names of productive authors becomes necessary. The improvement of some institutes may be attributed to the emphasis by universities for academics to publish in journals indexed by the ISI databases and Scopus. Information about trends and productivity reveals the intellectual output of toxicology works published in Scopus and is useful to university administrators when evaluating the yearly performance of university faculties in the light of university rankings among Arab universities.

In most MEA countries, the underdevelopment of toxicology is primarily due to improper educational policies. This region still lacks well-defined and elaborate postgraduate toxicology programmes at the university level, and there is a shortage of human resources in this field. Therefore, the formulation of a life sciences curriculum that comprises basic and applied toxicology and environmental sciences-related subject matter is needed. Recently, most institutes of education in MEA countries have undertaken a few important steps in this direction. Young researchers in MEA countries understand the principles of toxicology only at higher degree levels, that is, doctoral degree or postgraduate programmes. Therefore, the sharing of relevant research questions by developed and developing countries can lead to research opportunities [46]. Lastly, developing a culture of research in MEA countries, led by a researcher with an expertise in biostatistics and epidemiology, and who may be based in academia, is another necessary key to having a sustained productive research effort [46].

This study is not without limitations, most of which are the same as those of studies performed in other biomedical fields. First of all, we used Scopus criteria for including toxicology journals in our study. Articles published in nonScopus-cited journals were not included; however, they might contribute to scientific productivity. In addition, we searched only for journals included in the "Toxicology"related term of SCOPUS, although many articles in the toxicology field are published in other toxicology journals, with a wider field of interest, such as medicine and pharmacology. Furthermore, some conference abstracts may be published by certain journals which may be then published in the same or different journals in different year as original journal articles. Another limitation is that some international journals do not recognise countries like Palestine as a separate country and publications from Palestine may be affiliated with Israel as a country. Therefore, some publications from Palestine might be missed from our analysis.

\section{Conclusions}

This study, to our knowledge, is the first detailed analysis of the research publication output in the field of toxicology of an institution setting in MEA countries. This paper's main goal is to direct attention and to open the doors for a scientific discussion among toxicology professionals and academics. The present data show a promising rise and a good start for toxicology research activity in toxicology journals from the Arab world. Research output is low in some countries, which can be improved by investing in more international and national collaborative research projects in the field of Toxicology. Epidemiology of poisoning or case reports in toxicology are neglected in the MEA region. Most toxicology aspects, such as epidemiological data, are suitable for regional journals rather than international journals. Thus, MEA countries are recommended to establish peer-reviewed journals to promote science in middle- and low-income countries that could be submitted for indexing in Scopus.

\section{Abbreviations}

Al: Adjustment index; GDP: Gross domestic product; IF: Impact factor; IRB: Institutional review board; ISI: Institute for Scientific Information; JCR: Journal citation reports; KSA: Kingdom of Saudi Arabia; MEA: Middle Eastern Arab; SAR: Syrian Arab Republic; UAE: United Arab Emirates.

\section{Competing interests}

The authors declare that they have no competing interests.

\section{Authors' contributions}

All authors were involved in drafting the article, and all authors approved the final version to be submitted for publication. SZ conceived of the study and design, organized and supervised the data collection, and provided analysis, interpretation, and writing. SA and WS participated in the study design, and provided critical revision of manuscript for important intellectual content. RA was involved in concept and editing the manuscript.

\section{Acknowledgements}

The authors would like to thank An-Najah National University for giving the opportunities to access most recent information sources such as Scopus database.

\section{Author details}

${ }^{1}$ Poison Control and Drug Information Center (PCDIC), College of Medicine and Health Sciences, An-Najah National University, Nablus 44839, Palestine. ${ }^{2}$ Department of Pharmacology and Toxicology, College of Medicine and Health Sciences, An-Najah National University, Nablus 44839, Palestine. ${ }^{3} \mathrm{WHO}$ Collaborating Centre for Drug Information, National Poison Centre, Universiti Sains Malaysia (USM), Penang 11800, Malaysia. ${ }^{4}$ Department of Clinical and Community Pharmacy, College of Medicine and Health Sciences, An-Najah National University, Nablus 44839, Palestine.

Received: 25 December 2013 Accepted: 7 January 2014

Published: 21 January 2014

\section{References}

1. Wallin JA: Bibliometric methods: pitfalls and possibilities. Basic Clin Pharmacol Toxicol 2005, 97(5):261-275. 
2. Bissar-Tadmouri N, Tadmouri GO: Bibliometric analyses of biomedical research outputs in Lebanon and the United Arab Emirates (1988-2007). Saudi Med J 2009, 30(1):130-139.

3. Lin JY, Rosenblatt D: Shifting patterns of economic growth and rethinking development. J Econ Policy Reform 2012, 15(3):171-194

4. Falagas ME, Pitsouni El, Malietzis GA, Pappas G: Comparison of PubMed, Scopus, web of science, and Google scholar: strengths and weaknesses. FASEB J 2008, 22(2):338-342.

5. Sweileh WM, Zyoud SH, Sawalha AF, Abu-Taha A, Hussein A, Al-Jabi SW: Medical and biomedical research productivity from Palestine, 2002-2011. BMC Res Notes 2013, 6:41.

6. Benamer HT, Bredan A, Bakoush O: Scientific publication productivity of Libyan medical schools: a bibliometric study of papers listed in PubMed, 1988-2007. Educ Health (Abingdon) 2009, 22(2):310.

7. Diab MM, Taftaf RM, Arabi M: Research productivity in Syria: quantitative and qualitative analysis of current status. Avicenna J Med 2011, 1(1):4-7.

8. Tadmouri GO, Tadmouri NB: Biomedical research in the Kingdom of Saudi Arabia (1982-2000). Saudi Med J 2002, 23(1):20-24.

9. Afifi M: Egyptian biomedical publications in PubMed, 1996-2005. J Egyp Public Health Assoc 2007, 82(1-2):91-104

10. Tadmouri GO, Bissar-Tadmouri N: Biomedical publications in an unstable region: the Arab world, 1988-2002. Lancet 2003, 362(9397):1766.

11. Miro O, Montori E, Ramos X, Galicia M, Nogue S: Trends in research activity in toxicology and by toxicologists in seven European countries. Toxicol Lett 2009, 189(1):1-4.

12. Biglu MH, Omidi Y: Scientific profile of pharmacology, toxicology and pharmaceutics fields in Middle East countries: impacts of Iranian scientists. Inter J Adv Pharmaceut Sci 2010, 1:122-127.

13. Delirrad M, Rashidi A, Karimi S: A bibliometric analysis of toxicology publications of Iran and Turkey in ISI web of science. Iranian J Toxicol 2013, 6(19):735-745.

14. Jones AW: Impact of JAT publications 1981-2003: the most prolific authors and the most highly cited articles. J Anal Toxicol 2004, 28(7):541-545.

15. Bird SB: Journal impact factors, $h$ indices, and citation analyses in toxicology. J Med Toxicol 2008, 4(4):261-274.

16. Zyoud SH, Al-Jabi SW, Sweileh WM, Awang R: A bibliometric analysis of research productivity of Malaysian publications in leading toxicology journals during a 10-year period (2003-2012). Hum Exp Toxicol 2013. Article in Press.

17. De Battisti F, Salini S: Robust analysis of bibliometric data. Stat Methods Appl 2013, 22(2):269-283.

18. Milat AJ, Bauman AE, Redman S, Curac N: Public health research outputs from efficacy to dissemination: a bibliometric analysis. BMC Public Health 2011, 11:934.

19. Tan J, Fu H-Z, Ho Y-S: A bibliometric analysis of research on proteomics in science citation index expanded. Scientometrics 2013.

20. Tess BH, Furuie SS, Castro RC, BarretoMdo C, Nobre MR: Assessing the scientific research productivity of a Brazilian healthcare institution: a case study at the Heart Institute of Sao Paulo, Brazil. Clinics (Sao Paulo) 2009, 64(6):571-576.

21. Kira A, Glover M, Bullen C, Viehbeck S: Publications as an indicator of increased tobacco control research productivity (quantity and quality) in New Zealand. Nicotine Tob Res 2011, 13(6):474-478.

22. McDonald PW, Viehbeck S, Robinson SJ, Leatherdale ST, Nykiforuk Cl, Jolin MA: Building research capacity for evidence-informed tobacco control in Canada: a case description. Tob Induc Dis 2009, 5(1):12.

23. Scopus: Sciverse Scopus fact sheet. SciVerse ${ }^{\circledast}$ Scopus. Amsterdam, Netherlands: Elsevier B.V. [http://info.sciencedirect.com/UserFiles/ sciverse scopus content coverage 0.pdf] Accessed on 19 October, 2012.

24. Burnham JF: Scopus database: a review. Biomed Digit Libr 2006, 3:1

25. World Bank Group: Countries and Economies 2012; 2013. [http://data. worldbank.org/country] Accessed on 25 November, 2013.

26. De Granda-Orive Jl, Alonso-Arroyo A, Roig-Vazquez F: Which data base should we use for our literature analysis? Web of science versus SCOPUS. Arch Bronconeumol 2011, 47(4):213.

27. Tadmouri GO, Bissar-Tadmouri N: A major pitfall in the search strategy on PubMed. Saudi Med J 2004, 25(1):7-10.

28. Kulkarni AV, Aziz B, Shams I, Busse JW: Comparisons of citations in web of science, scopus, and google scholar for articles published in general medical journals. JAMA 2009, 302(10):1092-1096.
29. Benamer HT, Bakoush O: Arab nations lagging behind other Middle Eastern countries in biomedical research: a comparative study. BMC Med Res Methodol 2009, 9:26.

30. Bredan A, Benamer $\mathrm{H}$, Bakoush O: Visibility of Arab countries in the world biomedical literature. Libyan J Med 2011, 6:6325

31. Shaban SF, Abu-Zidan FM: A quantitative analysis of medical publications from Arab countries. Saudi Med J 2003, 24(3):294-296.

32. Cheng T, Zhang G: Worldwide research productivity in the field of rheumatology from 1996 to 2010: a bibliometric analysis. Rheumatology (Oxford) 2013, 52(9):1630-1634.

33. Soteriades ES, Falagas ME: A bibliometric analysis in the fields of preventive medicine, occupational and environmental medicine, epidemiology, and public health. BMC Public Health 2006, 6:301.

34. Jang DH, Rusyniak DE: Hard impact: journal impact factor and JMT. J Med Toxicol 2011, 7(4):256-258.

35. loannidis JP: Concentration of the most-cited papers in the scientific literature: analysis of journal ecosystems. PLoS One 2006, 1:e5.

36. Callaham $M$, Weber $E$, Wears $R$ : Citation characteristics of research published in emergency medicine versus other scientific journals. Ann Emerg Med 2001, 38(5):513-517.

37. World Health Organization: WHO Report on the Global Tobacco Epidemic, 2011: Warning About the Dangers of Tobacco; 2011. [http://whqlibdoc.who.int/ publications/2011/9789240687813_eng.pdf] Accessed on 23 September 2013

38. Afshari R: What is the "Best Research" for low income countries? Asia Pacific J Med Toxicol 2013, 2(1):1.

39. Afshari R: A new horizon to medical toxicology in Asia Pacific region. Asia Pacific J Med Toxicol 2012, 1(1):2.

40. Kidd M, Hubbard C: Introducing Journal of Medical Case Reports. J Med Case Rep 2007, 1:1

41. Jones AW: Impact factors of forensic science and toxicology journals: what do the numbers really mean? Forensic Sci Int 2003, 133(1-2):1-8.

42. Dawson $\mathrm{AH}$ : Comment on editorial; best research for low income countries. Asia Pacific J Med Toxicol 2013, 2(2):76.

43. Figg WD, Dunn L, Liewehr DJ, Steinberg SM, Thurman PW, Barrett JC, Birkinshaw J: Scientific collaboration results in higher citation rates of published articles. Pharmacotherapy 2006, 26(6):759-767.

44. Lee $S$, Bozeman B: The impact of research collaboration on scientific productivity. Social Studies Sci 2005, 35(5):673-702.

45. Abramo G, D'Angelo CA, Di Costa F: Research collaboration and productivity: is there correlation? High Educ 2009, 57(2):155-171.

46. Hoffman RJ: Knowledge, not funding is the most important research resource. Asia Pacific J Med Toxicol 2013, 2(2):77.

doi:10.1186/1478-4505-12-4

Cite this article as: Zyoud et al:: A bibliometric analysis of toxicology research productivity in Middle Eastern Arab countries during a 10-year period (2003-2012). Health Research Policy and Systems 2014 12:4.

\section{Submit your next manuscript to BioMed Central and take full advantage of:}

- Convenient online submission

- Thorough peer review

- No space constraints or color figure charges

- Immediate publication on acceptance

- Inclusion in PubMed, CAS, Scopus and Google Scholar

- Research which is freely available for redistribution 